\title{
Prosthetic complications of fixed dental prostheses supported by locking-taper implants: a retrospective study with a mean follow-up of 5 years
}

Wen mo Gao, Wei Geng ${ }^{*}$ and Chen chen Luo

\begin{abstract}
Background: Restoration with locking-taper implants is a widely used methodology. However, conical connection systems such as locking-taper implant systems have rarely been examined. This study provides a retrospective investigation of locking-taper fixed restorations, mainly focusing on prosthetic complications.

Methods: Patients undergo treatment with conical connected implants from 2008 to 2010 were examined. Preparation of the implant sites was performed according to the standard procedures for the Bicon system. Bone healing took over 6 months, and the prosthetic procedure was initiated thereafter. Integrated abutment crowns or gold porcelain crowns were used, and the prosthesis type was a single crown or a fixed dental prosthesis. Once the crown was in place, its occlusion was thoroughly checked and adjusted, and then the crown was glazed or finely polished. The Kaplan-Meier method was used to calculate the cumulative complication-free rates for 5 and 10 years. Additionally, a Cox regression model was used to identify the factors that independently influenced the results. Implant survival and marginal bone loss were also investigated.
\end{abstract}

Results: A total of 392 patients who underwent 541 implants and 434 locking taper implant-based restorations from 2008 to 2010 were examined. The overall 5-year cumulative complication-free rate was $83.34 \%$. The most common prosthetic complication was veneer chipping, with a frequency of $67.53 \%$. According to the Cox regression model, the complication-free rate of integrated abutment crowns was significantly higher than that of gold porcelain crowns, that of molar regions was significantly higher than that of premolar regions, and that of females was significantly higher than that of males. Only three implant failures happened, and the mean marginal bone loss values at 1-year, 5-years and 10-years were $0.25 \mathrm{~mm}(95 \% \mathrm{Cl} \pm 0.12), 0.40 \mathrm{~mm}(95 \% \mathrm{Cl} \pm 0.03)$ and $0.51 \mathrm{~mm}(95 \% \mathrm{Cl} \pm 0.05)$, respectively.

Conclusion: Veneer chipping was the most common complication with locking-taper implant-supported fixed restorations. The incidence of complications for IACs is significantly higher than that for GPCs. Age, location, and prosthesis type are not determinants of prosthetic complications. Besides, the long-term clinical effect of locking-taper implant can meet the clinical needs. The bone tissue level around the implant can maintain long-term stability.

Keywords: Prosthetic complications, Implant restorations, Implantology, Locking-taper implants

\footnotetext{
*Correspondence: gengwei717@aliyun.com; 13439478685@163.com Department of Dental Implant Center, Beijing Stomatological Hospital, School of Stomatology, Capital Medical University, No. 4 Tian Tan Xi Li, Dongcheng District, Beijing 100050, People's Republic of China
} original author(s) and the source, provide a link to the Creative Commons licence, and indicate if changes were made. The images or other third party material in this article are included in the article's Creative Commons licence, unless indicated otherwise in a credit line to the material. If material is not included in the article's Creative Commons licence and your intended use is not permitted by statutory regulation or exceeds the permitted use, you will need to obtain permission directly from the copyright holder. To view a copy of this licence, visit http://creativecommons.org/licenses/by/4.0/. The Creative Commons Public Domain Dedication waiver (http://creativeco mmons.org/publicdomain/zero/1.0/) applies to the data made available in this article, unless otherwise stated in a credit line to the data. 


\section{Background}

Implant treatment is becoming an increasingly popular choice for patients. A study showed that the implant survival rate of implant supported fixed prostheses (single crowns) was satisfactory [1]. However, complications arising from implant treatment are a bothersome issue for both doctors and patients $[1,2]$. Additionally, it has been reported that screw failure is a large concern for clinicians and patients [3]. As shown by a systematic review, $12.7 \%$ of implant supported fixed prostheses are affected by loosening after an average of 5 years [4]. Screw loosening can be caused by inadequate tightening torque, fatigue, the settling effect, micromotion, and excessive bending [5]. Thus, an appropriate preload is crucial for the joint stability. Although screw loosening does not necessarily lead to prosthesis failure, it can allow plaque deposits to form that result from microgaps and micromotion $[6,7]$, and these deposits can lead to further biological complications, such as peri-implantitis or peri-implant mucositis. Accordingly, pure (screwless) implant systems, such as conical connection systems that are fixed by only friction, have been developed.

The implant-abutment interface of the conical connection system is mostly Morse taper connected with cold-welding $[8,9]$, thus eliminating the prosthetic complications associated with screws [10]. The implant-abutment connections were usually less than $1.5^{\circ}$ Morse tapers with an internal cone [8]. The abutment is fixed only by means of friction. Moreover, cold-welding provides a well-closed abutment-implant interface, which is conducive to plaque control and may reduce the incidence of biological complications [11]. Compared to screw-based systems, locking-taper connections are more stable and can better resist lateral and axial forces $[8,12]$.

Many studies and systematic reviews $[13,14]$ have assessed the complication rates of implant-supported fixed prostheses. However, most of these earlier studies focused on butt-joint screw- type implant-abutment connection systems, while relatively few have examined conical connection systems $[15,16]$. The present study was a long-term retrospective study that aimed to assess the correlations between the cumulative prosthetic complication-free rate of fixed prostheses supported by locking-taper implants and various relevant factors, such as patient age, patient sex, prosthesis position, jaw position, restoration type (single crown (SC) or fixed partial prosthesis crown (FDP)), and the prosthetic materials that were used. The marginal bone loss (MBL) and implant survival rate were also investigated.

\section{Methods}

\section{Study design and sample}

The current work was a long-term retrospective clinical study with an average follow-up of 5 years. All patients who were referred to the Beijing Stomatological Hospital during 2000-2010 and received at least one Bicon (type of implant type, Bicon, Boston, MA, US) implant were enrolled in the study. This article has been reported using a statement from STROBE (Strengthening the Reporting of Observational studies in Epidemiology) as closely as possible. This study was performed in accordance with the Declaration of Helsinki and was approved by the Ethics Committee (Scientific Research/Technical Branch) of Beijing Stomatological Hospital affiliated with Capital Medical University (Approval Number: CMUSH-IRB-KJPJ-2019-12). Informed consent was obtained from all the participants enrolled in the present study.

The exclusion criteria were as follows:

1. Patients for whom the implant failed in regard to osseointegration before the prosthetic procedures;

2. Patients with implants supported over dentures;

3. Patients whose medical records cannot provide sufficient information (specific restoration materials);

4. Patients with CAD-CAM zirconia or non-precious metal porcelain crowns;

5. Patients for whom a guided bone regeneration (GBR) procedure was used.

6. Patients for whom a sinus floor elevation procedure was used.

The relevant factors that were considered were

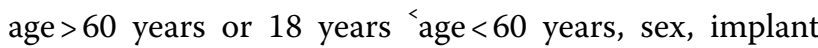
position (anterior, premolar, or molar region), implant location (maxilla or mandible), prosthesis type ( single crowns(SCs) or fixed dental prosthesis (FDP), and restoration material (integrated abutment crowns(IACs) or gold alloy porcelain crowns(GPCs)). Information was collected from the patients' medical records and disaggregated based on the relevant factors to identify those that had an impact on the incidence rate of prosthetic complications. Specific definitions of the complications are presented in Table 1. Both IACs and GPCs are most commonly used at our hospital, while non-precious metal porcelain and zirconia crowns are seldomly used. Therefore, the latter two types of crowns were not included in the study. Since the present study mainly focused on the prosthetic complications, implants that failed before prosthetic procedures started were excluded. Implants that demonsteated failed osseointegration, i.e., within 6 months of the implant operation, were excluded. To make the marginal bone loss (MBL) values more comparable, patients for whom a sinus floor elevation procedure 
Table 1 Definition of the complications

\begin{tabular}{ll}
\hline Prosthetic complications & Definition \\
\hline Veneer chipping & $\begin{array}{l}\text { Veneer chipping or the fracture of IACs or GPCs, metal base exposed or not } \\
\text { Lbutment loosening }\end{array}$ \\
Abutment fracture & $\begin{array}{l}\text { restoration interface } \\
\text { Crocture on the abutments, including cracks or complete fracture }\end{array}$ \\
Decementation & Decentation in GPCs \\
\hline
\end{tabular}

This study focused mechanical complications, including veneer chipping/fracture, abutment loosening/fracture, and restoration decementation. Specific definitions of the complications are presented in this table

and a guided bone regeneration (GBR) procedure were used were excluded.

\section{Surgical and restorative procedures}

All implants were Bicon (type of implant type, Bicon, Boston, MA, US) American implants. The implant-abutment connections were $1.5^{\circ}$ locking tapers with an internal cone. Preparation of the implant sites was performed according to the standard procedures for the Bicon system. Bone healing took over 6 months, and the prosthetic procedure was initiated thereafter. All the impressions were taken using polyether silicone rubber (type of rubber type, 3 M, St. Paul, MN, US). IACs or GPCs were used, and the prosthesis type was an SC (single crown) or an FDP (fixed dental prosthesis). Integrated abutment crowns (IACs) are a typical and fully retrievable type of restoration that is supported by locking-taper implants. IACs are metal-resin crowns made from a titanium base and a composite resin veneer of Ceramage (type of veneer resin, SHOFU, JP). Ceramage(Type of veneer resin, SHOFU, JP) is a fiber-reinforced composite resin with filler particles that has a higher strength than conventional resin [17]. The GPCs were cemented with glass ionomer cement. Once the crown was in place, its occlusion was thoroughly checked and adjusted, and then the crown was glazed (GPCs) or finely polished (IACs).

\section{Clinical and radiographic examination}

This study focused on prosthetic complications, including veneer chipping/fracture, abutment loosening/ fracture, and restoration decementation. These complications were recorded as endpoint events. Biological complications were not examined in the present study. Implant failures were counted in this study. Implant failures in this study were defined as the failures occurring after prosthetic loading, and other failures occuring before prosthetic loading were not included. Implant failures in this study included peri-implantitis, progressive bone loss and implant body fracture.

Intraoral periapical radiographs were taken for each implant at 1-, 5- and 10- year follow-up examinations time respectively for comparative analysis and measurements (Digimizer, ver.4.3.4, MedCalc Software, Ostend, Belgium). The distance from the most coronal bone to the margin of the implant neck was measured. To eliminate the impact of the distortion of images, the distance was calculated as the ratio of the implant length measured on the radiograph to the actual implant length. Mesial and distal distances were measured for each implant, and the average of the two was considered as the final MBL. The process was repeated by the same observer for three times, and the final result was the average of the three measurements.

\section{Data management and statistics}

A database was prepared using Microsoft Excel. The populations of the different variable groups were assessed, and the data were then transferred to GraphPad Prism (version 7.0) for statistical analysis. Kaplan-Meier estimators were used to obtain survival curves (restoration based), from which the cumulative complication-free rates were calculated (95\% CI). Log-rank and GehanBreslow-Wilcoxon tests were used to assess whether there were significant differences in the survival curves between the different groups $(\mathrm{p}<0.05$ represented a significant difference). In addition, implant failures and MBL were also investigated.

Based on the statistical results, the factors that had an impact on prosthetic complications were identified. After single-factor analysis was performed, multifactor analysis using a Cox regression model (SPSS version 23.0) was used to identify the factors that independently influenced the results. Factors with a p value $<0.1$ were included in the Cox regression model.

\section{Results}

\section{Preliminary statistical results}

A total of 392 patients who had at least one Bicon implant installed between January 2008 and January 2010, including a total of 541 implants and 434 restorations (201 for male patients and 233 for female patients), were included in the study. The average age of the patients was 
Table 2 Study variables

\begin{tabular}{lll}
\hline $\begin{array}{l}\text { Study variables } \\
\mathbf{N} \%\end{array}$ & $\%$ \\
\hline Gender & & \\
Male & 201 & 46.3 \\
Female & 233 & 53.67 \\
Age & & \\
Age $>60$ & 72 & 16.5 \\
18<age $<60$ & 362 & 83.4 \\
Material & & 32.03 \\
IAC & 139 & 67.97 \\
MC & 295 & 75.35 \\
Type & & 24.65 \\
SCs & 327 & \\
FDPs & 107 & 7.37 \\
Implant position & & 21.6 \\
Anterior region & 32 & 70.97 \\
Premolar region & 94 & 48.16 \\
Molar region & 308 & 51.8 \\
Implant location & & \\
Maxilla & 209 & \\
Mandible & 225 & \\
\hline Thele & &
\end{tabular}

The relevant factors were considered to be age ( $>60$ years or $<60$ years), gender, implant position (anterior, premolar, or molar region), implant location (maxilla or mandible), prosthesis type (SC or FPPC), and restoration material (IAC or GPC). Distribution by different factors are shown in Table 1

Table 3 Total prosthetic complications

\begin{tabular}{lllll}
\hline Complication & $\mathbf{2}$ years & $\mathbf{2 - 5}$ years & $\mathbf{> 5}$ year & Total \\
\hline Veneer chipping & 17 & 19 & 15 & 52 \\
Abutment loosening & 0 & 2 & 5 & 7 \\
Abutment fracture & 0 & 1 & 0 & 1 \\
Crown loosening/shedding & 6 & 8 & 3 & 17 \\
\hline
\end{tabular}

Complication distribution by time is shown in Table 3. Totally 78 of 451 prostheses suffered from prosthetic complications. Two single IACs suffered from veneer chipping within 3 months, and these cases are counted as early restoration failures. Specific statistics are shown as above

43.07 years (restoration-based). The patient distribution is shown in Table 2.

The complication distribution by time is shown in Table 3. Between 2008 and 2010, 77 of the 434 restorations were affected by prosthetic complications. Other mechanical complications, such as implant fracture, were not included since no implant fractures occurred. The most common prosthetic complication was veneer chipping (52), with a frequency of $67.53 \%$. Only one abutment fracture occurred in the 3rd year after the prosthesis placement. The complication frequencies are presented in Fig. 1.

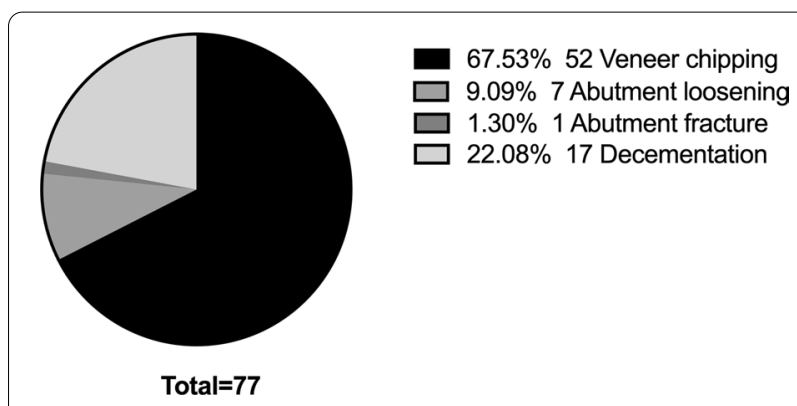

Fig. 1 Prosthetic complications distribution. In total, 77 prostheses suffered from the prosthetic complications. The most common mechanical complication is veneer chipping (52), followed by decementation (17) (which only occurrs in GPCs). The specific complication frequencies are presented in Fig. 1

A total of 3 implant failures occured in 3 patients, and Table 4 Failed implants

\begin{tabular}{lllll}
\hline Gender & Age & Site & $\begin{array}{l}\text { Time of failure(after } \\
\text { prosthetic loading) } \\
\text { (years) }\end{array}$ & Type of failure \\
\hline M & 56 & 36 & 2 & Peri-implantitis \\
M & 49 & 26 & 1 & Peri-implantitis \\
F & 52 & 47 & 4 & Peri-implantitis
\end{tabular}

A total of 3 implant failures happened in 3 patients respectively, details were shown in Table 4. All the 3 implants failed in 5 years after loading

Table 5 Marginal bone loss disaggregated by time

\begin{tabular}{lllll}
\hline Year & Mean & SD & Median & $\mathbf{9 5 \% ~ C l}$ \\
\hline 1 & 0.25 & 0.25 & 0.24 & $0.13-0.37$ \\
5 & 0.40 & 0.29 & 0.41 & $0.37-0.43$ \\
10 & 0.51 & 0.30 & 0.52 & $0.46-0.56$ \\
\hline
\end{tabular}

A mean MBL at 1-year, 5 -year and 10-year was $0.25 \mathrm{~mm}(95 \% \mathrm{Cl} \pm 0.12), 0.40 \mathrm{~mm}$ $(95 \% \mathrm{Cl}: \pm 0.03)$ and $0.51 \mathrm{~mm}(95 \% \mathrm{Cl} \pm 0.05)$, respectively. The bone tissue level around the implant can maintain long-term stability

details are shown in Table 4. The MBL values at the 1-, 5- and 10-follow up were $0.25 \mathrm{~mm}(95 \% \mathrm{CI} \pm 0.12 \mathrm{~mm})$, $0.40 \mathrm{~mm} \quad(95 \% \quad \mathrm{CI} \pm 0.03 \mathrm{~mm}), \quad 0.51 \quad \mathrm{~mm} \quad(95 \%$ $\mathrm{CI} \pm 0.05 \mathrm{~mm}$ ), respectively (Table 5).

\section{Univariate survival analysis}

The overall prosthesis survival curve is presented in Fig. 2. The overall 5 -year cumulative complication-free rate was $83.84 \%$, while the 10 -year rate was $67.48 \%$ (Table 6). Significant differences in the survival curves were observed in the material and position groups $(\mathrm{p}<0.05)$. Conversely, no significant differences were observed in the sex, age, location, or prosthesis-type groups $(\mathrm{p}>0.05)$. 


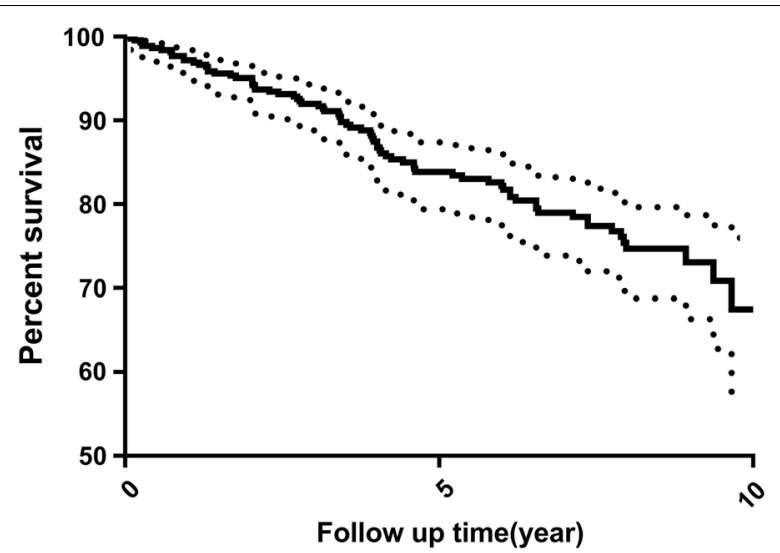

Fig. 2 Overall prosthesis mechanical complication-free survival curve

There were significant differences in the early phase for the position groups (Gehan-Breslow-Wilcoxon test: $\mathrm{p}=0.02$ ). For the location groups, prostheses in the mandibles showed a slightly higher complication incidence rate than those in the maxilla $(\mathrm{p}=0.09)$. Furthermore, the female group had a slightly higher complication rate than the male group $(p=0.05)$, and the older group had a slightly higher complication rate than the younger group $(\mathrm{p}=0.33)$. However, these differences were not statistically significant. No notable differences were observed between these groups $(p=0.67)$. Nevertheless, these factors may influence each other. Multivariate analysis with Cox regression was used to identify the factors that independently influenced the results. To avoid the omission of possible influential factors, factors with a $\mathrm{p}$ value $<0.1$ were included in the Cox regression model, including sex $(\mathrm{p}=0.0526)$, material $(\mathrm{p}=0.04)$, implant position $(\mathrm{p}=0.04)$ and location $(\mathrm{p}=0.09)($ Table 6$)$.

\section{Multivariate regression analysis}

Multivariate regression analysis with Cox regression was used to examine the influential factors, including sex, material, implant position and location. The results are shown in Table 7. After multivariate regression analysis, the results showed that material, gender and tooth position were independent factors affecting the survival time. According to the HR value, the material was an independent protective factor, indicating that IACs had a longer survival time than GPCs $(\mathrm{p}=0.043, \mathrm{HR}=0.615(95 \% \mathrm{CI}$ $[0.385 ; 0.984]))$. Sex was an independent risk factor, and the female survival time was shorter than the male survival time $(\mathrm{p}=0.041, \mathrm{HR}=1.627$ (95\% CI [1.021;2.592])). The survival time of premolars was longer than that of

Table 6 Cumulative complication-free rates and curve comparison

\begin{tabular}{|c|c|c|c|c|c|c|}
\hline \multirow[t]{2}{*}{ Study variables } & \multicolumn{2}{|c|}{ Kaplan-Meier } & \multicolumn{2}{|c|}{ Log-rank test } & \multicolumn{2}{|c|}{ Gehan-Breslow-Wilcoxon test } \\
\hline & $5 y$ & $10 y$ & Chi-square & P-value & Chi-square & P-value \\
\hline \multicolumn{7}{|l|}{ Gender } \\
\hline Male & $87.0 \%$ & $73.0 \%$ & 3.758 & 0.0526 & 3.358 & 0.07 \\
\hline Female & $80.87 \%$ & $64.05 \%$ & & & & \\
\hline \multicolumn{7}{|l|}{ Age } \\
\hline$>60$ & $76.23 \%$ & $67.47 \%$ & 0.946 & 0.33 & 1.235 & 0.27 \\
\hline$<60$ & $85.03 \%$ & 67.28 & & & & \\
\hline \multicolumn{7}{|l|}{ Material } \\
\hline IAC & $79.49 \%$ & $53.06 \%$ & 4.356 & 0.04 & 3.283 & 0.07 \\
\hline GPC & $85.04 \%$ & $73.31 \%$ & & & & \\
\hline \multicolumn{7}{|l|}{ Type } \\
\hline SCs & $84.01 \%$ & $54.70 \%$ & 0.181 & 0.67 & 0.215 & 0.64 \\
\hline FPPS & $83.53 \%$ & $75.27 \%$ & & & & \\
\hline \multicolumn{7}{|l|}{ Implant position } \\
\hline Anterior region & $85.02 \%$ & $77.94 \%$ & 6.703 & 0.04 & 7.542 & 0.02 \\
\hline Premolar region & $93.17 \%$ & $85.51 \%$ & & & & \\
\hline Molar region & $81.27 \%$ & $64.22 \%$ & & & & \\
\hline \multicolumn{7}{|l|}{ Implant location } \\
\hline Maxilla & $87.38 \%$ & $78.20 \%$ & 2.936 & 0.09 & 2.073 & 0.15 \\
\hline Mandible & $80.20 \%$ & $62.00 \%$ & & & & \\
\hline Total & $83.84 \%$ & $67.48 \%$ & & & - & \\
\hline
\end{tabular}


Table 7 Cox regression model of the four influencing factors

\begin{tabular}{lllllll}
\hline Influencing factors & $\boldsymbol{B}$ & SE & Wald & $\boldsymbol{P}$ & HR & HR 95\% Cl \\
\hline Material & -0.486 & 0.240 & 4.106 & 0.043 & 0.615 & $0.385-0.984$ \\
Location & 0.184 & 0.244 & 0.565 & 0.452 & 1.201 & $0.745-1.939$ \\
Gender & 0.487 & 0.238 & 4.192 & 0.041 & 1.627 & $1.021-2.592$ \\
Position & & & & & \\
Molar region & & & 5.098 & 0.078 & 0.923 & $0.363-2.348$ \\
Anterior region & -0.08 & 0.476 & 0.028 & 0.867 & 0.024 & 0.375 \\
Premolar region & -0.98 & 0.435 & 5.09 & $0.160-0.879$ \\
\hline
\end{tabular}

Multivariate regression analysis with Cox regression was used to examine the influential factors, including gender, material, implant position and location. After multivariate regression analysis, the results showed that material, gender and tooth position were independent factors affecting survival time

molars $(\mathrm{p}=0.024, \mathrm{HR}=0.375$ (95\% CI $[0.160 ; 0.879])$ ). The other indicators did not independently affect the survival time.

\section{Discussion}

A previous 5-year systematic review of the clinical outcomes of fixed complete dentures supported by implants showed that the survival rate of the implants was satisfactory but that the prosthetic complication rate was rather high [18]. Veneer chipping was the most common prosthetic complication. Other studies have also shown that the complication rates of implant-supported fixed prostheses have significantly increased over time [2, 19]. In most clinical studies regarding locking-taper systems, most of the prostheses that were examined were porcelain-fused-metal-fixed prosthetics, most commonly GPCs $[15,20,21]$. Compared to the number of studies on GPCs, far fewer studies have focused on metalacrylic prostheses, and most of these studies have mainly focused on complete dentures [22, 23]. The conclusion that veneer chipping is the most common prosthetic complication associated with titanium-acrylic complete dentures has been confirmed in other studies [22-24].

In the current study, prosthetic complications, such as abutment loosening and abutment fracture, occurred much less frequently than technical complications such as veneer chipping or decementation. This prosthetic complication distribution is similar to that observed in a previous retrospective study, in which only two abutment fractures and one case of abutment loosening were observed in the 80 subjects [10].

Screw-connected implant systems can have microgaps of approximately $40-100 \mu \mathrm{m}$ at the interface between the implant and abutment $[25,26]$, which will accumulate plaques and increase the probability of peri-implantitis [6]. Locking-taper implant systems can greatly reduce the microgaps $(1-3 \mu \mathrm{m})$ compared to the former and thus may decrease the probability of peri-implantitis [11]. The implant survival in this study is satisfactory. Several other studies confirm that among all of the patients who met the inclusion criteria, only three implant failures occurred. All the three failed implants were peri-implantitis, which supported single crown prostheses. Although peri-implantitis occurred, the morbidity was greatly reduced compared to screw-connected implant systems $[1,27,28]$, which may be ascribed to the minute microgap of locking-taper implant systems. The present study revealed a stable MBL, at 1 year, 5 years and 10 years. Due to the high dropouts of the present study, the 10-year MBL values are for reference only. The results of MBL in the present study are similar to those of previous studies, which indicates that the long-term clinical outcome of locking-taper implants is satisfactory $[16,29]$. The results of MBL of the present study are similar to those of previous studies, which indicates that the long-term clinical outcome of locking-taper implant is satisfactory.

The results of the multifactor analysis are shown in Table 7.According to a previous study, the use of Ceramage can reduce the risk of veneer chipping in comparison to that of conventional metal-based porcelain crowns since its elastic modulus is close to that of natural teeth [30]. However, in the present study, compared with the GPCs, the survival time of the IAC crowns was significantly shorter, which was consistent with the results of the univariate analysis. The interfacial adhesion of titanium and acrylic is mainly due to physical adhesion, and some chemical adhesion is provided by coupling agents. These types of adhesion are weaker than the chemical adhesion between gold alloy and porcelain. We believe that these different interfacial bonding forces are the root cause of the results presented in this study. Similarly, a recently published meta-analysis reported that the chipping rate of porcelain-fused-metal-fixed prostheses is 9\%, which is much lower than that of metal-resin prostheses (27\%) [31]. However, prosthetic complications, such as abutment loosening and abutment fracture, were presented by GPCs. These results may be the result of the cushioning effect of the resin, which accommodates 
some of the mechanical force that is applied to implant components. IACs have unique advantages. The resin exhibits excellent stress resistance, reducing damage to the implant [32].The bonding of IACs is completed outside of the mouth, reducing the potential irritation of the periodontal tissue by the adhesive. Additionally, the fact that IACs can be repaired in the mouth by clinicians can greatly reduce procedure times. In contrast, the repair of metal-based porcelain crowns, including alternatives such as GPCs, can be difficult. The strength of the metal base can be reduced by repeated firings, during which tiny cracks may arise [33].

After removing the confounding factors, there was no significant difference in the survival time of the prosthesis in the maxilla and mandible, and the difference between the two groups was further narrowed, which may indicate that the effect of the jawbone density was not as large as expected. The molar region presented higher complication rates than that of the premolar region, and a significant difference was observed (log-rank test $\mathrm{p}<0.05$ ). Similarly, it has been previously reported that prosthetic complications occur more frequently in the molar region because of the mechanical force conditions in that area [34]. Since the number of cases in the anterior tooth area was too small, the results of the anterior tooth area in this study were not statistically significant. A study have showed that the incidence of complications in the anterior tooth area was slightly lower than that in the posterior tooth area [20]. This may be related to the inclusion of both biological and repair complications in the study.

In contrast to the univariate analysis, there was a significant difference in survival time between the sex groups in the multivariate analysis. This may be because females typically exhibit better adherence than females and return more quickly for advice than men when complications occur, or the result may have been affected by other influencing factors.

This study was a retrospective survival analysis, and the results will inevitably deviate from those of prospective experiments. The sample size of some groups in this study was small. For some variable groups, the differences were rather significant, such as those between the restoration type (FDPs: $\mathrm{SCs}=107: 327$ ), material (IACs: GPCs $=139: 295)$, and age $(>60$ years $:<60$ years $=72$ : 362 ). These differences may have impacted the statistical results to a certain degree. Biological complications and the survival rate require further prospective and longterm follow-up studies.

\section{Conclusions}

Veneer chipping is the most common prosthetic complication for both IACs and GPCs that are supported by locking-taper implants. Over time, the incidence of complications for IACs is significantly higher than that for GPCs. Significant differences were observed between the different prosthetic materials, placement positions and sexes. The bone tissue level around the locking-taper implant can maintain long-term stability.

\section{Acknowledgements \\ The authors kindly thank American Journal Experts (AJE) for professional English editing.}

\section{Authors' contributions}

W.G completed the data collection. C.Land W.G provided cases. W.G and W.G designed the observational clinical experiment scheme. W.G undertook figure editing and drafted the manuscript. All authors have read and approved the final manuscript.

\section{Funding}

This work was supported by the National Natural Science Foundation of China (Grant No. 62071313) for data statistical analysis and professional English editing.

\section{Declarations}

Ethics approval and consent to participate

This study was performed in accordance with the Declaration of Helsinki and was approved by the Ethics Committee (Scientific Research/Technical Branch) of Beijing Stomatological Hospital affiliated with Capital Medical University (Approval Number: CMUSH-IRB-KJ-PJ-2019-12). The informed consent was obtained from all the participants enrolled in the present study.

\section{Consent for publication}

Not applicable.

\section{Competing interests}

The authors do not have any potential conflicts of interest to indicate.

Received: 10 February 2021 Accepted: 9 September 2021

Published online: 27 September 2021

\section{References}

1. Germana De Villa Camargos D, MS1/Célio Jesus do Prado, DDS, MS, PhD2/ Flavio Domingues das Neves, DDS, MS, PhD2/Ivete Aparecida de Mattias Sartori, DDS, MS, PhD3: Clinical outcomes of single dental implants with external connections: results after 2 to 13 years. The International Journal of Oral \& Maxillofacial Implants 2012, 27.

2. Bragger U, Karoussis I, Persson R, Pjetursson B, Salvi G, Lang N. Technical and biological complications/failures with single crowns and fixed partial dentures on implants: a 10-year prospective cohort study. Clin Oral Implant Res. 2005;16(3):326-34.

3. Sadid-Zadeh R, Kutkut A, Kim H. Prosthetic failure in implant dentistry. Dent Clin N Am. 2015;59(1):195-214

4. Jung RE, Pjetursson BE, Glauser R, Zembic A, Zwahlen M, Lang NP. A systematic review of the 5 -year survival and complication rates of implantsupported single crowns. Clin Oral Implant Res. 2008;19(2):119-30.

5. Schmitt CM, Nogueira-Filho G, Tenenbaum HC, Lai JY, Brito C, Doring H, Nonhoff J. Performance of conical abutment (Morse taper) connection implants: a systematic review. J Biomed Mater Res A. 2014;102(2):552-74.

6. Tallarico M, Canullo L, Caneva M, Ozcan M. Microbial colonization at the implant-abutment interface and its possible influence on periimplantitis: a systematic review and meta-analysis. J Prosthodont Res. 2017;61(3):233-41.

7. Yuya SDC. Implant-abutment connections: a review of biologic consequences and peri-implantitis implications. Int J Oral Maxillofac Implants. 2017;32(6):1296-307. 
8. Sannino G, Barlattani A. Mechanical evaluation of an implant-abutment self-locking taper connection: finite element analysis and experimental tests. Int J Oral Maxillofac Implants. 2013;28(1):e17-26.

9. Norton MR. Assessment of cold welding properties of the internal conical interface of two commercially available implant systems. J Prosthet Dent. 1999;81(2):159.

10. Carlo Mangano M, Bartolucci G. Single tooth replacement by Morse taper connection implants: a retrospective study of 80 implants. Int J Oral Maxillofac Implants. 2001;16:66.

11. Dibart S, Su MF, Skobe Z. In vitro evaluation of the implant-abutment bacterial seal: the locking taper system. Int J Oral Maxillofac Implants. 2005:20:732-7.

12. Norton M. An in vitro evaluation of the strength of an internal conical interface compared to a butt joint interface in implant design. Clin Oral Implants Res. 2010;8(4):66.

13. Jung RE, Zembic A, Pjetursson BE, Zwahlen M, Thoma DS. Systematic review of the survival rate and the incidence of biological, technical, and aesthetic complications of single crowns on implants reported in longitudinal studies with a mean follow-up of 5 years. Clin Oral Implant Res. 2012;23(Suppl 6):2-21.

14. Romeo E, Storelli S. Systematic review of the survival rate and the biological, technical, and aesthetic complications of fixed dental prostheses with cantilevers on implants reported in longitudinal studies with a mean of 5 years follow-up. Clin Oral Implant Res. 2012;23(Suppl 6):39-49.

15. Mangano C, laculli F, Piattelli A, Mangano F. Fixed restorations supported by Morse-taper connection implants: a retrospective clinical study with 10-20 years of follow-up. Clin Oral Implant Res. 2015;26(10):1229-36.

16. Mangano F, Macchi A, Caprioglio A, Sammons RL, Piattelli A, Mangano C. Survival and complication rates of fixed restorations supported by locking-taper implants: a prospective study with 1 to 10 years of followup. J Prosthodont. 2014;23(6):434-44.

17. Rosenthal L, Pescatore C. A new system for posterior restorations: a combination of ceramic optimized polymer and fiber-reinforced composite. Pract Periodont Aesth Dent. 1997;9:66.

18. Panos Papaspyridakos D, Chen C-J, Chuang S-K, Weber H-P, Gallucci O. A systematic review of biologic and technical complications with fixed implant rehabilitations for edentulous patients. Int J Oral Maxillofac Implants. 2012;66:27.

19. Wittneben JG, Salvi GE, Bürgin W, Hicklin S, Brägger U. Complication and failure rates with implant-supported fixed dental prostheses and single crowns: a 10-year retrospective study. Clin Implant Dent Relat Res. 2014:16:66.

20. Mangano F, Lucchina AG, Brucoli M, Migliario M, Mortellaro C, Mangano C. Prosthetic complications affecting single-tooth Morse-taper connection implants. J Craniofac Surg. 2018;29(8):2255-62.

21. Mangano F, Colombo M, Mangano C. Clinical evaluation of 762 singletooth, locking-taper implants: a prospective study with 1- to 12-years of follow-up. J Dent Oral Care Med. 2016;6:66.
22. Javier Ventura EJ-C, Romero J, Francisco F. Tooth fractures in fixed full-arch implant-supported acrylic resin prostheses: a retrospective clinical study. Int J Prosthodont. 2016;161:66.

23. Bozini T, Tzanas K, Garefis P. A meta-analysis of prosthodontic complication rates of implant-supported fixed dental prostheses in edentulous patients after an observation period of at least 5 years. Int J Oral Maxillofac Implants. 2011;26:66.

24. Priest G, Smith J, Wilson MG. Implant survival and prosthetic complications of mandibular metal-acrylic resin implant complete fixed dental prostheses. J Prosthet Dent. 2014;111(6):466-75.

25. Weng D, Nagata MJ, Bell M, Bosco AF, de Melo LG, Richter EJ: Influence of microgap location and configuration on the periimplant bone morphology in submerged implants. An experimental study in dogs. Clin Oral Implants Res. 2008, 19(11):1141-47.

26. Todescan FF, Pustiglioni FE, Imbronito AV, Albrektsson T, Gioso M. Influence of the Microgap in the Peri-implant hard and soft tissues: a histomorphometric study in dogs. Int J Oral Maxillofac Implants. 2002;17(4):66.

27. Aglietta M, Siciliano VI, Zwahlen M, Bragger U, Pjetursson BE, Lang NP, Salvi GE. A systematic review of the survival and complication rates of implant supported fixed dental prostheses with cantilever extensions after an observation period of at least 5 years. Clin Oral Implant Res. 2009;20(5):441-51.

28. Pjetursson BE, Thoma $D$, Jung $R$, Zwahlen $M$, Zembic A. A systematic review of the survival and complication rates of implant-supported fixed dental prostheses (FDP s) after a mean observation period of at least 5 years. Clin Oral Implants Res. 2012;23:22-38.

29. Coelho PG, Sudack P, Suzuki M, Kurtz KS, Romanos GE, Silva NR. In vitro evaluation of the implant abutment connection sealing capability of different implant systems. J Oral Rehabil. 2008;35(12):917-24.

30. Krejci I, Lutz F, Gautschi L. Wear and marginal adaptation of composite resin inlays. J Prosth Dent. 1994:72(3):233-44.

31. Att ABSA-AW. Effect of prosthetic material on the outcome of dental implants supporting implant-supported dentures: a meta analysis. Clin Oral Implants Res. 2017;28:66.

32. MCLaren EARR, Devaud V. Considerations in the use of polymer and fiberbased indirect restorative materials. Pract Periodontics Aesthet Dent. 1999;11(4):66

33. Sun Ying $W Z$, Wang $B$. The influence of repeated firings on the remained porcelain rate. J Pract Stomatol. 2002;18:66.

34. Kopp C. Branemark osseointegration. Prognosis and treatment rationale. Dent Clin of N Am. 1989;33(4):66.

\section{Publisher's Note}

Springer Nature remains neutral with regard to jurisdictional claims in published maps and institutional affiliations.
Ready to submit your research? Choose BMC and benefit from:

- fast, convenient online submission

- thorough peer review by experienced researchers in your field

- rapid publication on acceptance

- support for research data, including large and complex data types

- gold Open Access which fosters wider collaboration and increased citations

- maximum visibility for your research: over $100 \mathrm{M}$ website views per year

At BMC, research is always in progress.

Learn more biomedcentral.com/submissions 